\title{
Protective effects of total glucosides of paeony and the underlying mechanisms in carbon tetrachloride-induced experimental liver injury
}

Ying Qin, Ya-ping Tian

Department of Clinical Biochemistry, Chinese People's Liberation Army General Hospital, Beijing, China

Submitted: 16 September 2010

Accepted: 30 November 2010

Arch Med Sci 2011; 7, 4: 604-612

DOI: 10.5114 /aoms.2011.24129

Copyright @ 2011 Termedia \& Banach

\section{Abstract}

Introduction: We explored the protective effects of total glucosides of paeony (TGP) and the underlying mechanisms in carbon tetrachloride $\left(\mathrm{CCl}_{4}\right)$-induced experimental liver injury in mice.

Material and methods: Chronic liver damage was induced by intraperitoneal injection of $\mathrm{CCl}_{4}(0.5 \mu \mathrm{l} / \mathrm{g})$ three times per week for 8 weeks. Mice also received 25,50 or $100 \mathrm{mg} / \mathrm{kg}$ TGP. Liver sections were stained with haematoxylin/eosin. Serum amino transferases, lipid peroxidation and tumour necrosis factor- $\alpha$ (TNF- $\alpha$ ) levels were determined using commercial assays. Quantitative real-time polymerase chain reaction was used to determine the changes in hepatic TNF- $\alpha, C O X-2$, iNOS and HO-1 expression. Protein levels of nitric oxide synthase, cyclooxygenase-2, haem oxygenase-1 and cytochrome P450 2E1 were determined by western blotting.

Results: Histological results showed that TGP improved the $\mathrm{CCl}_{4}$-induced changes in liver structure and alleviated lobular necrosis. The increases in serum protein and hepatic mRNA expression of TNF- $\alpha$ induced by $\mathrm{CCl}_{4}$ treatment were suppressed by TGP. Total glucosides of paeony also attenuated the increase the expression in iNOS and CYP2E1 but augmented the increase in HO-1. The mRNA and protein expression levels of inducible $\mathrm{HO}-1$ increased significantly after $\mathrm{CCl}_{4}$ treatment.

Conclusions: Total glucosides of paeony protects hepatocytes from oxidative damage induced by $\mathrm{CCl}_{4}$. Total glucosides of paeony may achieve these effects by enhancing $\mathrm{HO}-1$ expression and inhibiting the expression of proinflammatory mediators.

Key words: total glucosides of paeony, liver injury, carbon tetrachloride.

\section{Introduction}

Previous studies have shown that carbon tetrachloride $\left(\mathrm{CCl}_{4}\right)$ enhances oxidative stress and the recruitment of inflammatory cells and therefore leads to hepatic architectural and functional damage [1-7]. Carbon tetrachloride impairs hepatocytes directly by altering the permeability of the plasma, lysosomal, and mitochondrial membranes. A single dose of $\mathrm{CCl}_{4}$ may lead to centrizonal necrosis and steatosis [8], while prolonged administration may induce liver fibrosis, cirrhosis, and even hepatocellular carcinoma ( $\mathrm{HCC})$. The lesions induced by carbon tetrachloride $\left(\mathrm{CCl}_{4}\right)$ replicate those seen in most cases of human liver diseases [9]. Therefore,

\author{
Corresponding author: \\ Ying Qin PhD \\ Prof. Ya-ping Tian \\ Department of Clinical \\ Biochemistry \\ Chinese People's Liberation \\ Army General Hospital \\ 28 Fu-Xing Road \\ 100853 Beijing, China \\ Phone: +861066939449 \\ Fax: +861066939374 \\ E-mail: \\ qinying301@yahoo.com.cn, \\ tianyp301@yahoo.com.cn
}


the experimental model of $\mathrm{CCl}_{4}$-induced hepatic injury has been used for many years to investigate the mechanisms involved in acute and chronic liver injury and to screen hepatoprotective drugs. Carbon tetrachloride-induced hepatic necrosis involves the bioactivation of a microsomal cytochrome P450dependent mono-oxygenase system, causing the formation of trichloromethyl free radicals and reactive oxygen species (ROS) that initiate lipid peroxidation and protein oxidation, resulting in hepatocellular membrane damage [10]. This process is followed by the release of inflammatory mediators from the activated hepatic macrophages, which are thought to potentiate $\mathrm{CCl}_{4}$-induced hepatic injury.

Paeonia lactiflora pall root, a Chinese traditional herbal medicine that has anti-inflammatory and antioxidative actions, has been used as a component of some hepatoprotective herb mixtures in China, Japan and Korea [11-13]. Total glucosides of paeony (TGP), extracted from P. lactiflora, contains paeoniflorin and other components such as hydroxyl-paeoniflorin, paeonin, albiflorin, and benzoylpaeoniflorin [14]. Paeoniflorin is the main active component of TGP, accounting for approximately $90 \%$ of the constituents of TGP. It has been shown that TGP has anti-inflammatory, antioxidative, hepatoprotective and immunoregulatory activities, without evident toxicity or side effects. Total glucosides of paeony has a long history of use in traditional Chinese medicine [15], particularly for the treatment of rheumatoid arthritis and systemic lupus erythematosus, and as a component of treatments for liver disease.

The present study was designed to evaluate whether TGP has any beneficial effect on liver histopathology or liver function in an experimental model of $\mathrm{CCl}_{4}$-induced chronic liver injury. We also investigated the underlying mechanisms based on the therapeutic role of TGP on the amelioration of inflammation and oxidative stress.

\section{Material and methods}

\section{Drugs and animals}

Total glucosides of paeony capsules (Ningbo Liwah Pharmaceutical CO., LTD, Zhejiang Province, China) were dissolved in saline to a concentration of $1.2 \mathrm{mg} / \mathrm{ml}$. Sodium carboxymethyl cellulose (0.5 g; CMC-Na; Sigma, St. Louis, MO, USA) was dissolved in $100 \mathrm{ml}$ of distilled water to provide a $0.5 \%(w / v)$ CMC-Na suspension. Biphenyldicarboxylate (BDP; Dezhou Deyao Pharmaceutical CO., LTD, Shandong Province, China) was dissolved in the $0.5 \%$ CMC-Na suspension to a concentration of $5.0 \mathrm{mg} / \mathrm{ml}$. Figure 1 shows the chemical structures of paeoniflorin, the main component of TGP, and BDP.

Male C57BL/6 mice weighing 25-30 g were obtained from the Institute of Laboratory Animal Sciences, Chinese Academy of Medical Sciences \& Peking Union Medical College (Beijing, China). The research protocol was in accordance with the principles approved by the animal ethics committee of Chinese People's Liberation Army General Hospital. Animals were housed at $23 \pm 2^{\circ} \mathrm{C}$ with a 12-h light/dark cycle and were allowed free access to standard laboratory chow and tap water. The mice were randomly divided into 6 groups: control, $\mathrm{CCl}_{4}$, TGP25, TGP50, TGP100 and BDP100 groups. The control group was intraperitoneally administered with the appropriate vehicles. The experimental groups were intraperitoneally injected with $\mathrm{CCl}_{4}(0.5 \mathrm{ml} / \mathrm{kg}, 1$ : 3 dilution in corn oil; Sigma) 3 times per week for 8 weeks. The mice in groups TGP25, TGP50 and TGP100 were given $25 \mathrm{mg} / \mathrm{kg}$, $50 \mathrm{mg} / \mathrm{kg}$ and $100 \mathrm{mg} / \mathrm{kg}$ TGP per day, respectively, by gavage, twice daily for 12 weeks. The mice in the
A

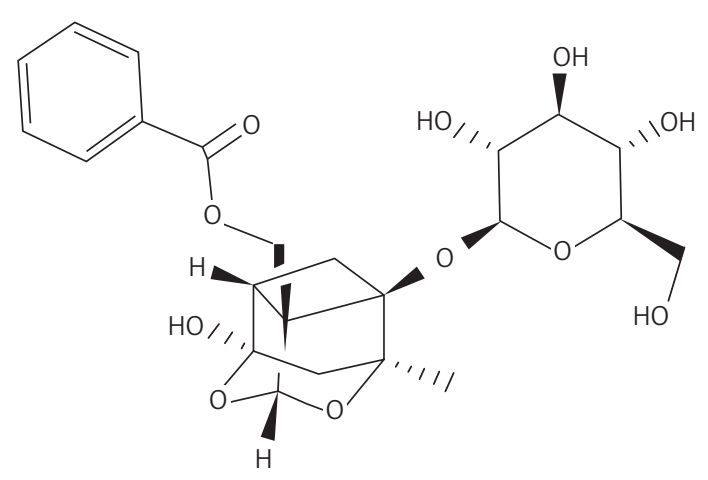

B

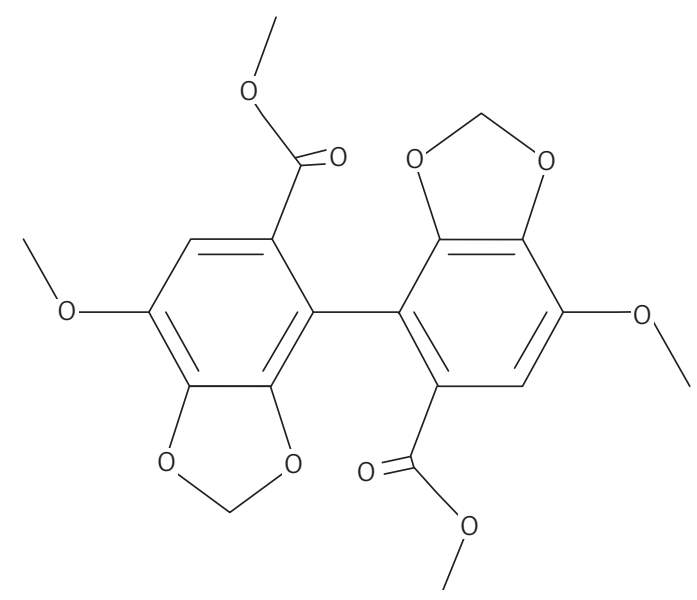

Figure 1. Chemical structures of paeoniflorin (A) and biphenyldicarboxylate (BDP) (B) $B D P$ - biphenyldicarboxylate 
BDP100 group were given BDP, a positive hepatoprotective control, at $100 \mathrm{mg} / \mathrm{kg}$ per day, once daily by gavage for 12 weeks. In the TGP and BDP groups, $\mathrm{CCl}_{4}$ administration was started in week 5 of administration and was continued to week 12 (i.e., for 8 weeks). At the end of the treatment period, the mice were fasted overnight and were sacrificed. Blood was collected from the abdominal aorta and the liver was removed and stored at $-80^{\circ} \mathrm{C}$ for later analysis.

\section{Mouse hepatic lipid peroxidation and serum assays}

Hepatic malondialdehyde (MDA) was measured as previously described [16-18]. In brief, $25 \mathrm{mg}$ of liver tissue was added to $250 \mu \mathrm{l}$ of radioimmunoprecipitation assay (RIPA) buffer containing protease inhibitors. This mixture was sonicated for $15 \mathrm{~s}$ at $40 \mathrm{~V}$ over ice and centrifuged at $1600 \times \mathrm{g}$ for $10 \mathrm{~min}$ at $4^{\circ} \mathrm{C}$. The supernatant was used for analysis. MDA was quantified using the thiobarbituric acid reaction as described by Ohkawa $[16,17]$, and measured using a thiobarbituric acid reactive substances (TBARS) assay (Cayman Chemical Co. Inc., MI, USA). Superoxide dismutase (SOD), nitric oxide synthase (iNOS), catalase (CAT) and glutathione peroxidase (GSH) were also quantified using appropriate assays (Cayman Chemical Co. Inc.) [16-18].

Serum alanine aminotransferase (ALT) and aspartate aminotransferase (AST) activities were determined using standard spectrophotometric procedures. Serum tumour necrosis factor $\alpha$ (TNF- $\alpha)$ was measured using an enzyme-linked immunosorbent assay (R\&D Systems, Minneapolis, MN, USA) according to the manufacturer's protocol.

\section{Histological and immunohistochemical analyses}

The liver tissues were immediately fixed in $4 \%$ paraformaldehyde, dehydrated, embedded in paraffin and sectioned. Formalin-fixed, paraffinembedded sections were cut and mounted on glass slides. Sections ( $5 \mu \mathrm{m}$ thick) were deparaffinised in xylene and stained with haematoxylin and eosin (H\&E) as described by Mihailovic et al. [19]. The immunohistochemical evaluation method was performed as described elsewhere [20]. Briefly, sections (5 $\mu \mathrm{m}$ thick) were cut from paraffinembedded testis tissues and mounted on slides. After deparaffinization and rehydration, they were placed in a 10-mM citrate buffer ( $\mathrm{pH}$ 6.0), followed by heating in a microwave oven for antigen retrieval. For this, three periods of 5 min each were used, after which the sections were treated with $3 \% \mathrm{H}_{2} \mathrm{O}_{2}$ in PBS ( $\mathrm{pH} 7.6$ ) for $20 \mathrm{~min}$. The sections were then incubated overnight at $4^{\circ} \mathrm{C}$ in PBS containing 3\% BSA and antibodies. Antibodies against TNF- $\alpha$ and nuclear factor $\kappa$ light chain enhancer in B cells p65 (NF-kB p65) (Santa Cruz Biotechnology Inc., Santa Cruz, CA, USA) were used at $1: 100$ and $1: 200$ dilution, respectively. The bound primary antibody was detected using biotinylated rabbit anti-mouse antibody (Zhongshan Golden Bridge, Beijing, China), and visualised using 3',3'-diaminobenzidine tetrahydrochloride. Sections were slightly counterstained with Mayer's haematoxylin and mounted.

\section{Real-time reverse transcription-polymerase chain reaction (qRT-PCR)}

Total RNA was extracted from the livers, isolated and purified with TRIzol reagent (Invitrogen, Carlsbad, CA, USA) and NucleoSpin ${ }^{\circledR}$ RNA clean-up kit (Macherey-Nagel, Duren, Germany). Messenger RNA (mRNA) analysis was carried out by qRT-PCR using LightCycler technology (Roche Diagnostics, Indianapolis, IN, USA) for continuous fluorescence detection. Complementary DNA (cDNA) was prepared for qPCR analyses using the M-MLV reverse transcriptase enzyme (Invitrogen-Gibco, Carlsbad, CA, USA) and random hexamers as primers, as described [21-23]. The primers for mouse $T N F-\alpha$, inducible nitric oxide synthase (iNOS), cyclooxygenase-2 (COX-2), and haem oxygenase-1 (HO-1) mRNA were used as previously reported [21-23]. The following sense and anti-sense primers were used for amplification: TNF- $\alpha$, 5'-CTACTCCCAGGTTCTCTTCAA-3' and 5'-GCAGAGAGGAGGTTGACTTTC-3' [21]; iNOS, 5'-CAGCTGGGCTGTACAAACCTT-3' and 5'-CATTGGAAGTGAAGCGTTTCG-3' [21]; COX-2, 5'-TTCAAATGAGATTGTGGAAAAAT-3' and 5'-AGATCATCTCTGCCTGAGTATCTT-3' [22]; HO-1, 5'-CGCCTTCCTGCTCAACATT-3' and 5'-TGTGTTCCTCTGTCAGCATCAC-3' [23], respectively. The reactions were performed using a LightCycler FastStart DNA Master SYBR Green I Kit (Roche Applied Science) according to the manufacturer's instructions. The PCR reaction conditions and the annealing temperature were as previously described [21-23]. $\beta$-Actin was used as a reference control gene to normalize the expression value of each gene [24]. The experiment was performed in triplicate for each gene, and the average expression value was computed for subsequent analysis. The results were compared using the $2^{-\Delta \Delta C T}$ method [25] and are expressed as $\log _{2}$ means \pm SD.

\section{Western blotting}

Liver whole protein was extracted and used for western blotting, which was performed as previously described [25]. Appropriate amounts of the protein extracts were fractionated by electrophoresis in 6-12\% SDS-polyacrylamide gels 
and transferred to nylon membranes. The nylon membranes containing the transferred proteins were pretreated with $1.0 \%$ non-fat dried milk in $50 \mathrm{mM}$ Tris (pH 8.0) and then incubated overnight with primary mouse monoclonal antibodies (Santa Cruz Biotechnology Inc.) against iNOS, COX-2, HO-1 and cytochrome P450 2E1 (CYP2E1), at dilutions $1: 300,1: 200,1: 500$ and $1: 400$, respectively. The membranes were washed and incubated with anti-mouse secondary antibodies (Zhongshan Golden Bridge Biotechnology, Beijing, China) and immunoreactivity was visualised by exposing X-ray film to blots incubated with $\mathrm{ECL}$ reagent (Amersham Biosciences, Piscataway, NJ, USA). Results were quantified using Image-Pro Plus software version 6.0 (Media Cybernetics Incorporated, Silver Spring, MD, USA).

\section{Statistical analysis}

Each experiment was performed at least 3 times. Data are means \pm standard deviation. Statistical analyses were performed by SPSS software (version 13.0, SPSS Inc., Chicago, IL, USA). One-way ANOVA with post hoc analysis using Bonferroni's method or Kruskal-Wallis $\mathrm{H}$ test on ranks was used for analysing results from different groups. Value of $p<0.05$ was considered statistically significant.

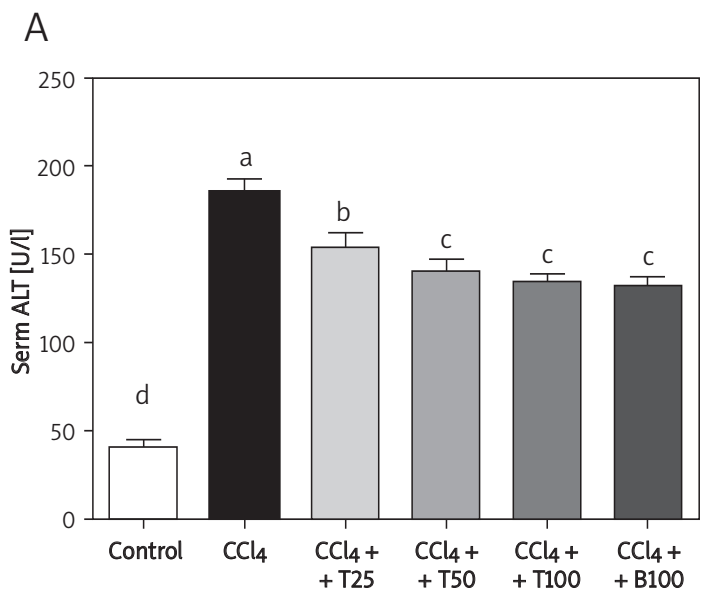

B

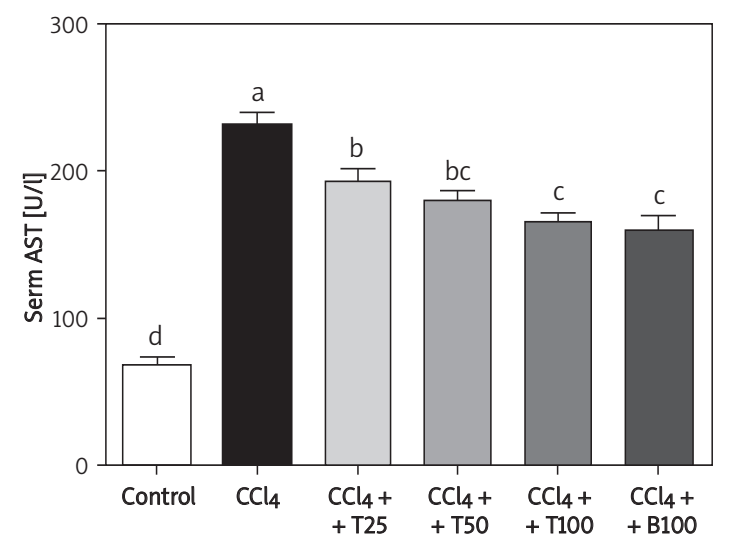

\section{Results}

\section{Serum TNF- $\alpha$ level and aminotransferase activities}

The serum TNF- $\alpha$ level was $8.5 \pm 2.2 \mathrm{pg} / \mathrm{ml}$ in the control group. In contrast, the serum TNF- $\alpha$ level was increased by almost 4-fold by $\mathrm{CCl}_{4}$, which was significantly attenuated by TGP. The serum ALT and AST activities in the control group were $40.5 \pm 10.9 \mathrm{U} / \mathrm{l}$ and $68.0 \pm 12.9 \mathrm{U} / \mathrm{l}$, respectively, and were markedly increased by $\mathrm{CCl}_{4}$ treatment. These increases were inhibited by treatment with $25 \mathrm{mg} / \mathrm{kg}, 50 \mathrm{mg} / \mathrm{kg}$ and $100 \mathrm{mg} / \mathrm{kg}$ TGP (Figure 2).

\section{Serum lipid peroxidation}

The serum MDA level was significantly increased in the $\mathrm{CCl}_{4}$-treated mice compared with the control group, and was attenuated by TGP or BDP. Similar to the MDA activities, the iNOS level was significantly increased in the $\mathrm{CCl}_{4}$-treated mice, and was attenuated by all doses of TGP and by BDP. The serum SOD activity in the $\mathrm{CCl}_{4}$-injected mice decreased to about $60 \%$ of the control value but this decrease was attenuated by all three doses of TGP. Changes in iNOS, CAT and GSH activities showed similar trends to that of SOD (Figure 3).

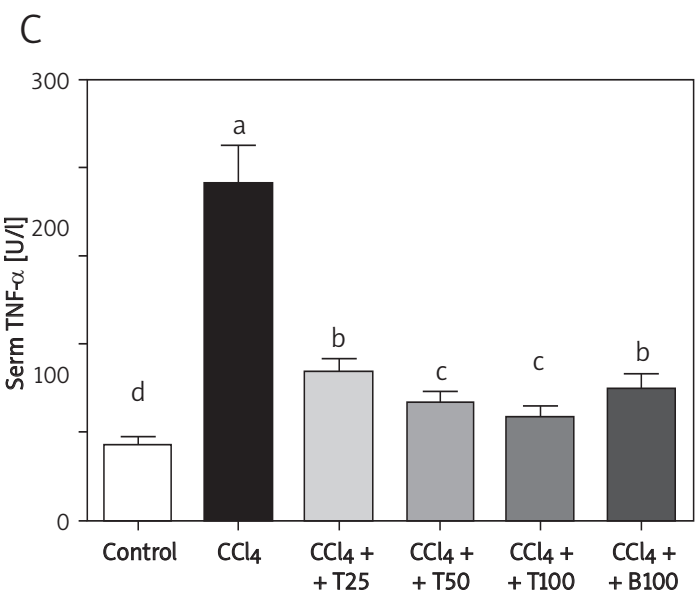

Figure 2. Serum ALT (A), AST (B) and TNF- $\alpha$ (C) levels after 8 weeks of $\mathrm{CCl}_{4}$ treatment. Values are means \pm SD of six mice per group. Significantly different $(p<0.05)$ from the control group. Means without a common letter differ at $p<0.05$ $\mathrm{CCl}_{4}-\mathrm{CCl}_{4}$ group, $\mathrm{CCl}_{4}+\mathrm{T}_{2} 5-\mathrm{TGP} 25$ group $\mathrm{CCl}_{4}+$ T50 - TGP 50 group, $\mathrm{CCl}_{4}+$ T100 - TGP 100 group 
A

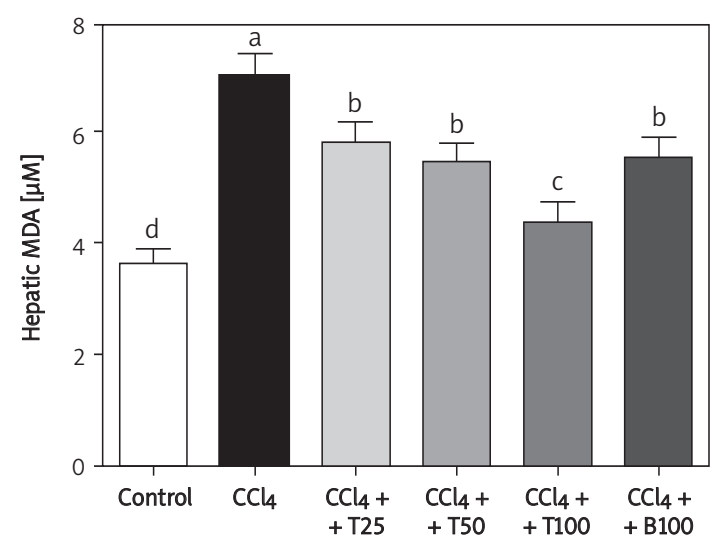

C

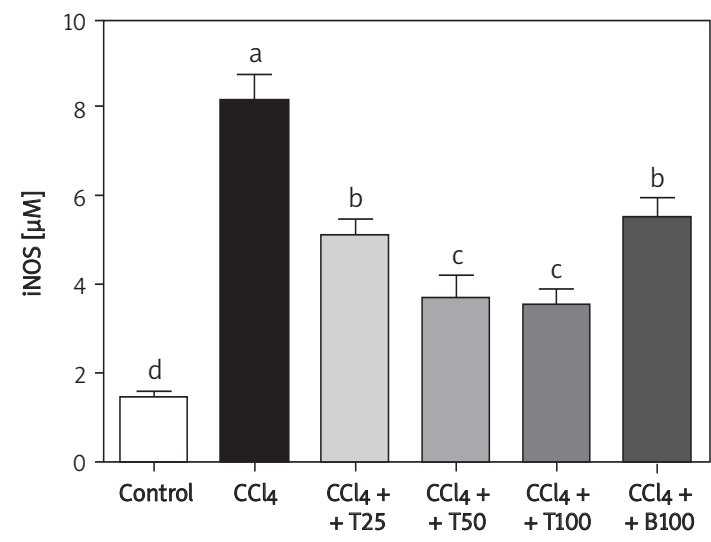

E

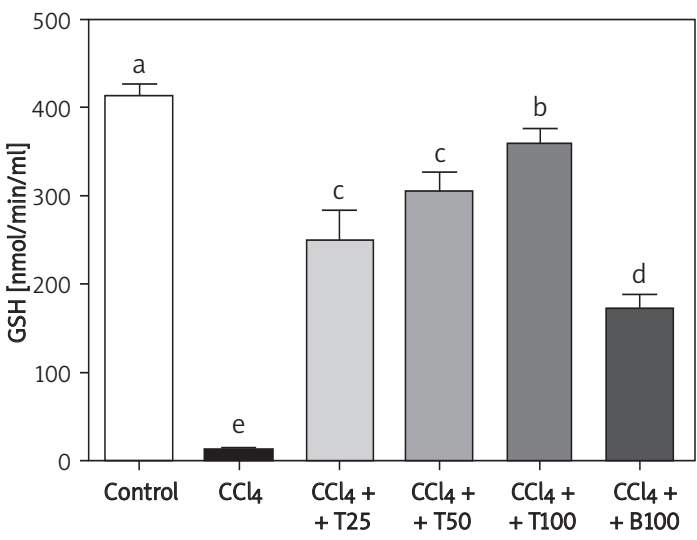

Histological and immunohistochemical analyses

Mice became lethargic and lean, and their fur became lustreless in the $\mathrm{CCl}_{4}$-treated group by 8 weeks of treatment. Liver samples were stained with H\&E to evaluate histopathological changes. The liver of mice in the control group showed a normal hepatic lobular architecture and cellular
B

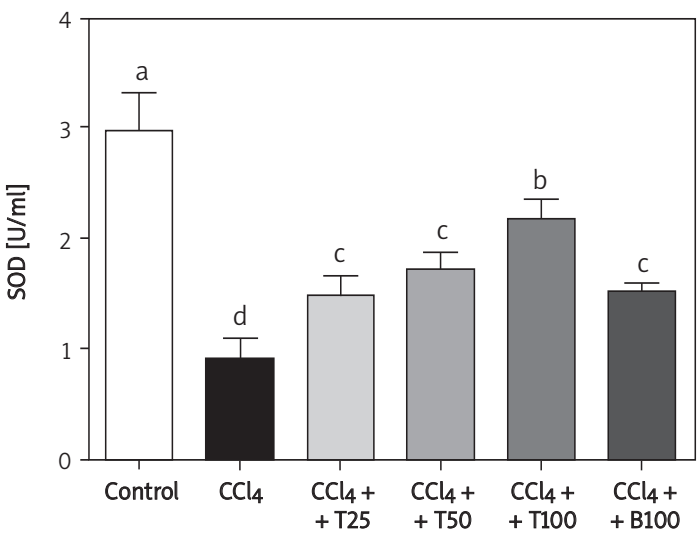

D

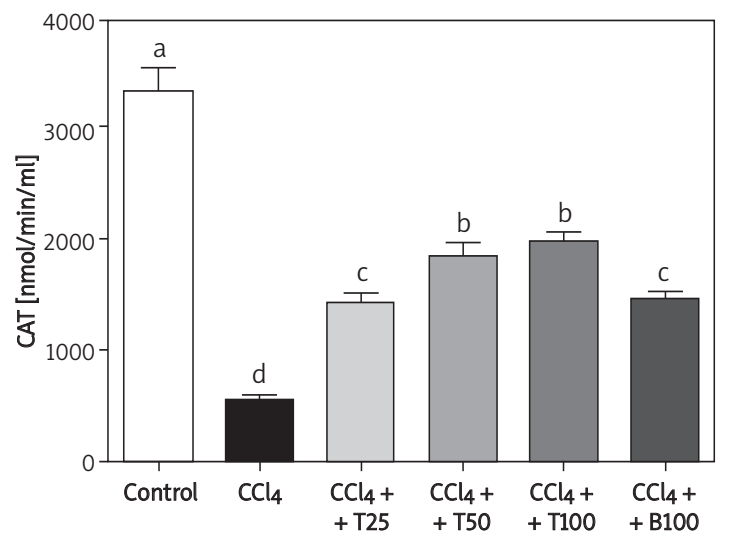

Figure 3. Hepatic MDA and lipid peroxidation after 8 weeks of $\mathrm{CCl}_{4}$ treatment. Hepatic MDA (A), and serum SOD (B), iNOS (C), CAT (D) and GSH (E) levels are shown. Values are means \pm SD of six mice per group. Significantly different $(p<0.05)$ from the control group. Means without a common letter differ at $p<0.05$

$\mathrm{CCl}_{4}-\mathrm{CCl}_{4}$ group, $\mathrm{CCl}_{4}+\mathrm{T} 25-\mathrm{TGP} 25$ group,

$\mathrm{CCl}_{4}+\mathrm{T} 25-\mathrm{TGP} 50$ group, $\mathrm{CCl}_{4}+$ T100-TGP 100 group

structure. In contrast, the histopathological analysis of the liver of mice from the $\mathrm{CCl}_{4}$-treated group showed extensive hepatocellular damage, with the presence of portal inflammation, marked neutrophilic infiltration, extensive fatty changes, centrizonal necrosis, Kupffer cell hyperplasia and hepatic fibrosis. These histopathological changes were ameliorated by daily administration of TGP or BDP for 12 weeks (Figure 4). 

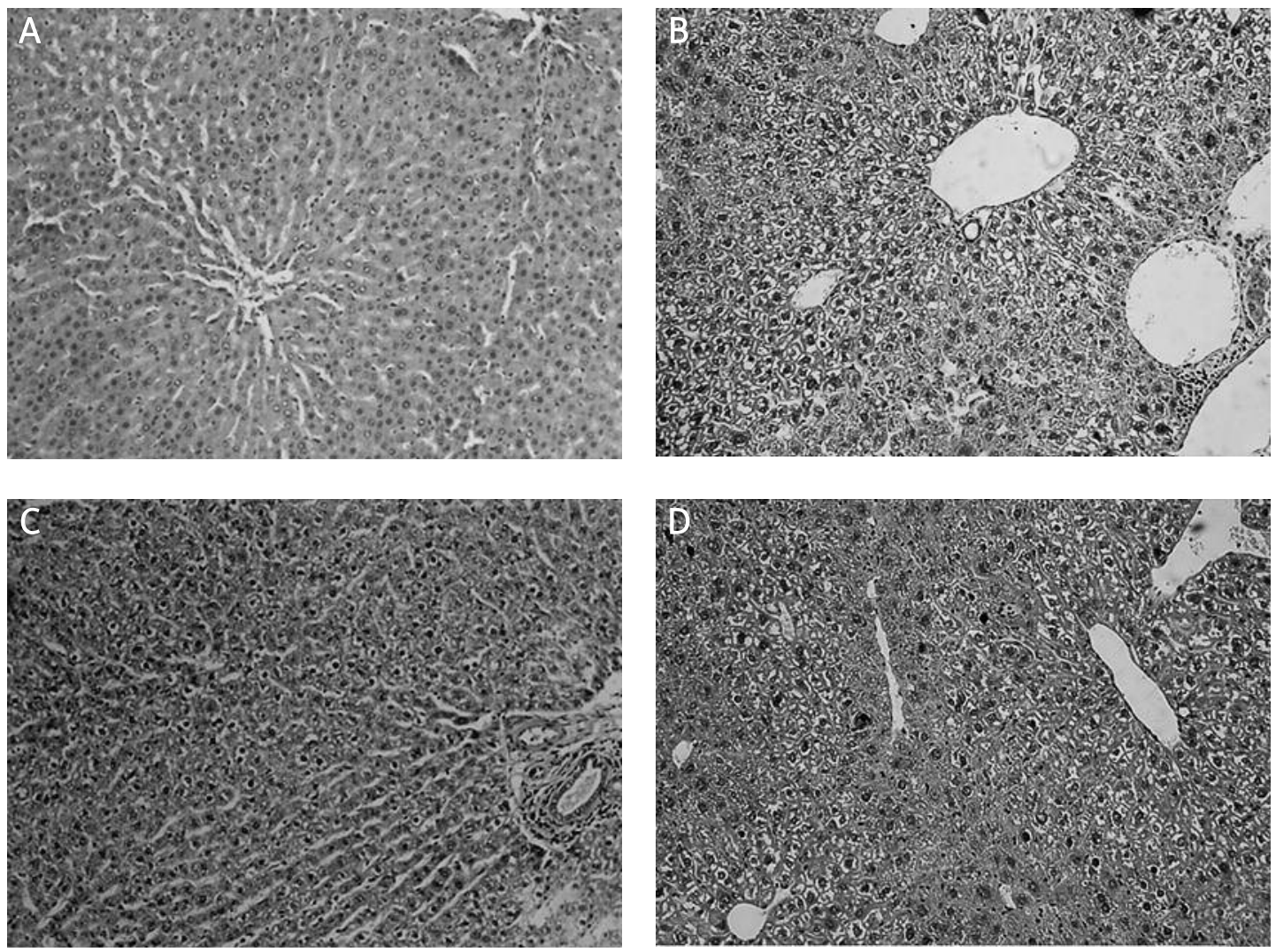

Figure 4. Effects of TGP on histological changes in the liver induced by $\mathrm{CCl}_{4}$ treatment for 8 weeks. A - the control group shows normal lobular architecture and cell structure. $\mathrm{B}$ - the $\mathrm{CCl}_{4}$-treated group shows extensive hepatocellular damage with the presence of portal inflammation, centrizonal necrosis, and Kupffer cell hyperplasia. $\mathbf{C}$ - mild portal inflammation, little hepatocellular necrosis and Kupffer cell hyperplasia are present in the $100 \mathrm{mg} / \mathrm{kg}$ TGP group. $\mathrm{D}$ - there were no marked improvements in $\mathrm{CCl}_{4}$-induced liver injury in the $100 \mathrm{mg} / \mathrm{kg}$ BDP group. Bars, $100 \mu \mathrm{m}$

Immunohistochemistry was performed to determine the changes in intrahepatic TNF- $\alpha$ and $\mathrm{NF}-\kappa \mathrm{B}$ p65 expression in the liver after $\mathrm{CCl}_{4}$ inducement. We found that TGP significantly reduced the hepatic expression of both proteins compared with the $\mathrm{CCl}_{4}$-treated mice. As shown in Figure 5 , daily administration of $100 \mathrm{mg} / \mathrm{kg}$ TGP for 12 weeks reduced the expression of TNF- $\alpha$ and $N F-\kappa B$ p65 in the liver and improved the histopathological changes and tissue fibrosis compared with mice treated with $\mathrm{CCl}_{4}$ alone.

\section{TNF- $\alpha$, iNOS, COX-2 and HO-1 mRNA expression}

Hepatic TNF- $\alpha$, iNOS, COX-2, and HO-1 mRNA expression were quite low in the control group. However, the mRNA expression levels of these genes were greatly increased by $\mathrm{CCl}_{4}$ administration. The increase in the expression of TNF- $\alpha$ and iNOS mRNA was suppressed by all three doses of TGP, whereas the mRNA expression of COX-2 was not affected by TGP. The mRNA expression of $\mathrm{HO}-1$ was increased by TGP (Figure 6).

\section{iNOS, COX-2, HO-1 and CYP2E1 protein expression}

The protein expression of iNOS and COX-2 was significantly higher in the $\mathrm{CCl}_{4}$-treated mice than in the control mice. The increase in the protein expression of iNOS and CYP2E1 was significantly suppressed by $100 \mathrm{mg} / \mathrm{kg}$ TGP; however, TGP had little effect on COX-2 protein expression, consistent with the changes in mRNA expression. The protein expression of HO-1 was significantly higher in the $\mathrm{CCl}_{4}$-treated group than in the control group, and this increase was augmented by $100 \mathrm{mg} / \mathrm{kg}$ TGP (Figure 7).

\section{Discussion}

In this study, we investigated the protective effects of TGP on $\mathrm{CCl}_{4}$-induced experimental liver injury in mice, and the underlying mechanism. It is generally accepted that $\mathrm{CCl}_{4}$-induced hepatotoxicity involves the metabolism of $\mathrm{CCl}_{4}$ by cytochrome P450 and the activation of Kupffer cells. The former leads to the generation of free radicals and lipid peroxidation, which may actuate the later. 

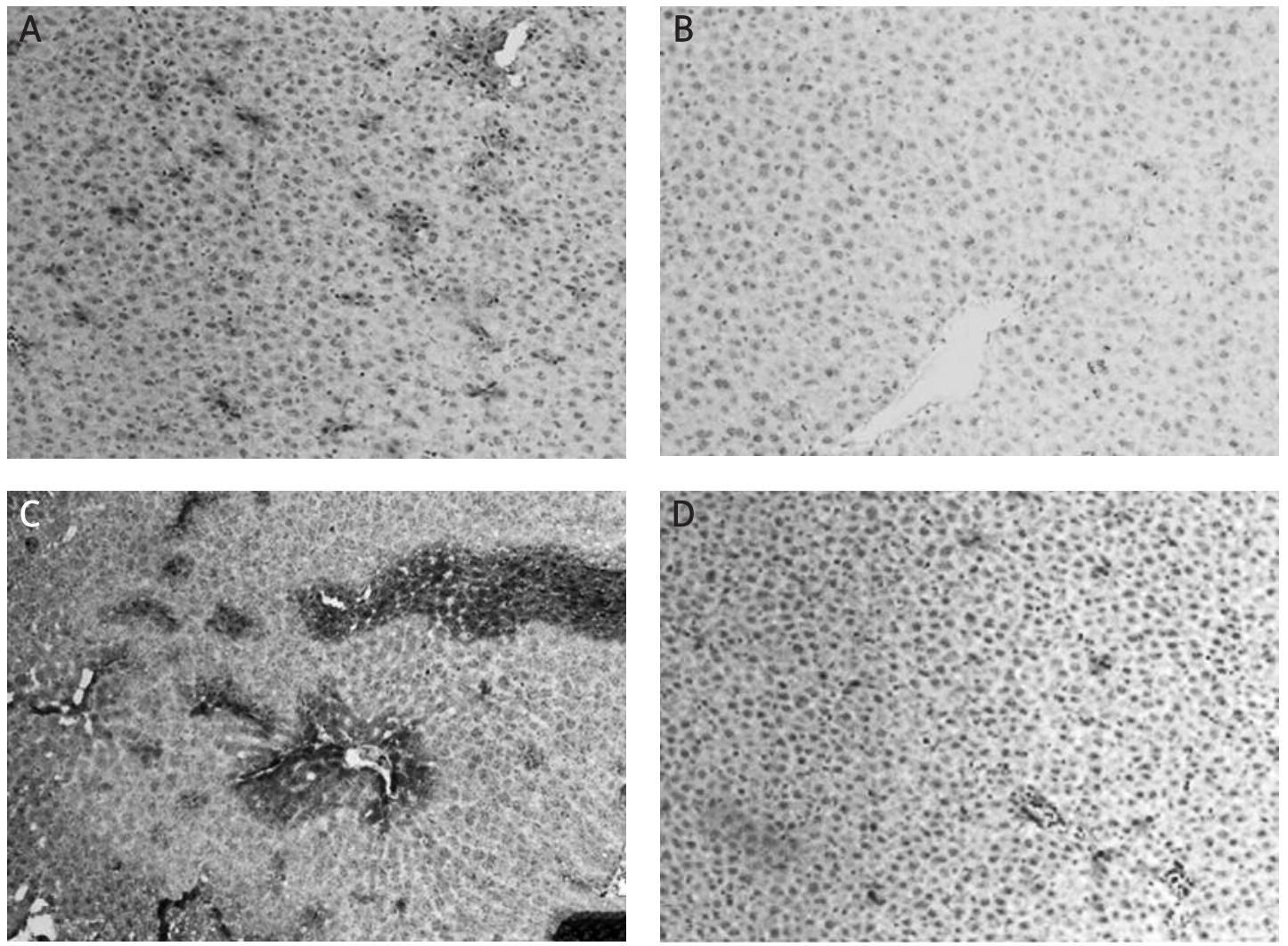

Figure 5. Immunohistochemical analyses showed that TGP suppressed the increased TNF- $\alpha$ and NF-кB 65 expression induced by 8 weeks of $\mathrm{CCl}_{4}$ treatment. A - TNF- $\alpha$ expression in the $\mathrm{CCl}_{4}$-treated group, B - the $100 \mathrm{mg} / \mathrm{kg}$ TGP-treated group, $\mathrm{C}-\mathrm{NF}-\mathrm{kB} 65$ expression in the $\mathrm{CCl}_{4}$-treated group, D - the $100 \mathrm{mg} / \mathrm{kg}$ TGP-treated group. Bars, $100 \mu \mathrm{m}$

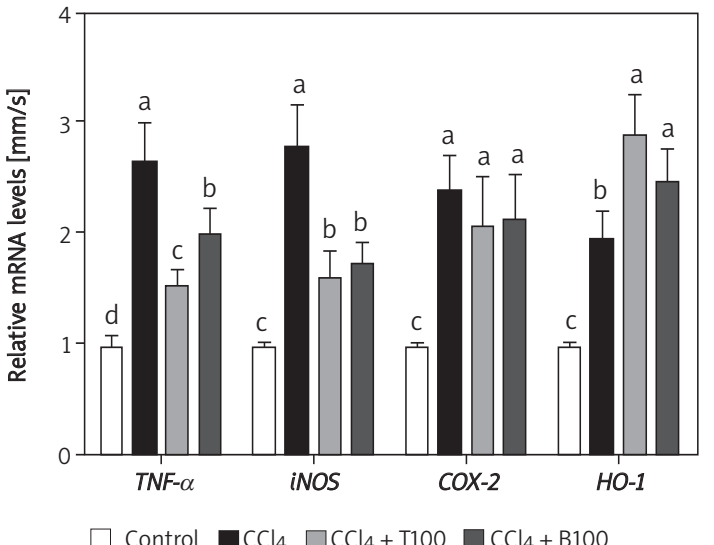

Figure 6. Effects of $100 \mathrm{mg} / \mathrm{kg}$ TGP on the mRNA expression of iNOS, COX-2 and HO-1 in the liver of $\mathrm{CCl}_{4}$-treated mice. Values are means \pm SD of five mice per group. Significantly different $(p<0.05)$ from the control group. Means without a common letter differ at $p<0.05$

T100 - TGP 100 group, BDP100 - BDP 100 group

Meanwhile, the activation of Kupffer cells is accompanied by the production of proinflammatory mediators [27, 28].

Total glucosides of paeony is relatively inexpensive, with negligible side effects, and shows great potential in the treatment of liver diseases. Previous studies have demonstrated that the antioxidative effects of TGP are mediated by the inhibition of thiobarbituric acid (TBA) reactive substance, an index of endogenous lipid peroxidation, and enhanced activities of antioxidant enzymes such as superoxide dismutase, catalase and glutathione peroxidase following cerebral ischaemia and immunological liver injury [29].

During hepatic injury, deteriorated integrity of the cellular membrane causes release of enzymes into the circulation, reflecting damage to the hepatic cells [30]. Thus, abnormally high levels of serum hepatospecific enzymes such as ALT and AST are regarded as good biomarkers for liver injury. We found that TGP inhibited the elevations of ALT and $\mathrm{AST}$ in $\mathrm{CCl}_{4}$-induced liver injury. The attenuated increase in serum ALT and AST levels suggests that TGP improved the structural integrity of the hepatocellular membrane, thus protecting mice against $\mathrm{CCl}_{4}$-induced hepatotoxicity. Histological analyses showed that $\mathrm{CCl}_{4}$ caused a variety of histological changes in the liver, including centrizonal necrosis, portal inflammation, Kupffer cell hyperplasia, extensive fatty changes, and even hepatic fibrosis and cirrhosis. These histo- 
pathological changes were significantly attenuated by TGP. Our findings suggest that the hepatoprotective effect of TGP was better or at least the same as that of BDP, a potent hepatoprotective agent. Although BDP has a marked ALT-lowering effect [31], this is transient and relapse is likely. Hence, its clinical application is limited. The present results suggest that TGP could be used to treat liver diseases.

Previous studies have indicated that the induction of $\mathrm{CYP} 2 \mathrm{E} 1$ by $\mathrm{CCl}_{4}$ in vivo leads to the generation of trichloromethyl free radicals and ROS, which initiate lipid peroxidation [32]. In turn, lipid peroxidation stimulates the expression of TNF- $\alpha$ and inflammatory mediators (e.g., iNOS and COX-2), and activates the signalling pathways that are classically associated with inflammation, such as NF- $\kappa B$, which might in turn further trigger the production of toxic compounds such as ROS or nitric oxide (NO), inflammatory cytokines and glutamate, thus causing liver damage [33]. Enhanced antioxidant activity may be one mechanism through which drugs may protect against $\mathrm{CCl}_{4}$-induced liver injury.

A recent report suggested that TGP ameliorated immunological hepatic fibrosis in rats caused by inhibitory oxidation and nitration [34]. In the present study, TGP inhibited CYP2E1 expression and consequently suppressed the increase in gene expression of TNF- $\alpha$ and iNOS, suggesting that TGP regulates $\mathrm{CCl}_{4}$-induced production of TNF- $\alpha$ and iNOS at the transcriptional level. Total glucosides of paeony blocked the $\mathrm{CCl}_{4}$-mediated oxidative stress and lipid peroxidation by significantly reducing the levels of by-products of lipid oxidation (i.e., hepatic MDA) and serum CAT levels, suppressing the activities of serum SOD and GSH, and inhibiting the increase in TNF- $\alpha$ levels. Concomitantly, the increased protein level of NF- $\kappa$ B was reduced by TGP treatment. These results indicate that TGP exerted its hepatoprotective effects by improving de novo protein synthesis, particularly of $\mathrm{HO}-1$, and counteracting the increased formation of free radicals. Moreover, HO-1 is believed to play an important protective role against oxidative injury [35]. Overexpression of HO-1 might be closely associated with the protective mechanism of some molecules against $\mathrm{CCl}_{4}$-induced hepatic injury. Our findings suggest that the gene expression of $\mathrm{HO}-1$ increased markedly within $24 \mathrm{~h}$ after $\mathrm{CCl}_{4}$ administration, and was maintained to the end of the study, comprising an important mechanism in the protective effects of TGP in $\mathrm{CCl}_{4}$-induced liver injury. However, in this study, the gene and protein expression of COX-2 increased significantly in response to $\mathrm{CCl}_{4}$ and was not affected by TGP. More studies are needed to examine this effect in more detail and explore the underlying mechanisms. Meanwhile, the physiology
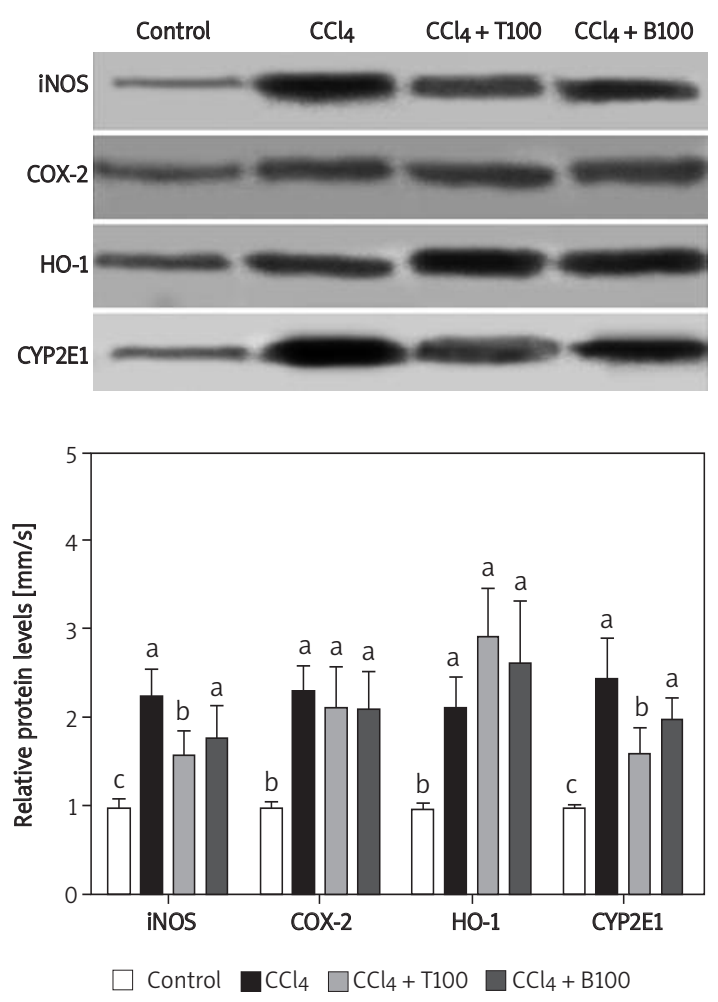

Figure 7. Effects of TGP $(100 \mathrm{mg} / \mathrm{kg})$ on the protein expression of iNOS, COX-2, HO-1 and CYP2E1 in the liver of $\mathrm{CCl}_{4}$-treated mice. Values are means $\pm \mathrm{SD}$ of five mice per group. Significantly different $(p<0.05)$ from the control group. Means without a common letter differ at $p<0.05$

T100 - TGP 100 group, BDP100 - BDP 100 group

and biochemistry of rodents are somewhat different from those observed in people. Further experimental studies in both the redones and humans and subsequently all phases of clinical trials in humans are also required before TGP is used in clinical study.

In conclusion, TGP protects the liver from $\mathrm{CCl}_{4}$-induced oxidative stress and the inflammatory response, without any known side effects. While the applicability of the findings of this work is very far from any conceivable clinical application in humans, the possible role of TGP as a promising therapeutic in human oxidative stress and inflammatory liver disease deserves further consideration. The potential for TGP in experimental and practical applications should be examined in future studies.

\section{Acknowledgments}

This study was supported partly by research grants from the National Science Foundation for Post-doctoral Scientists of China (No. 20080431363) and the National Natural Science Foundation of China (No. 20635002).

The authors declare that they have no competing interests. 


\section{References}

1. Kamalakkannan N, Rukkumani R, Varma PS, et al. Comparative effects of curcumin and an analogue of curcumin in carbon tetrachloride-induced hepatotoxicity in rats. Basic Clin Pharmacol Toxicol 2005; 97: 15-21.

2. Slater TF. Free-radical mechanisms in tissue injury. Biochem J 1984; 222: 1-15.

3. Poli G. Liver damage due to free radicals. Br Med Bull 1993; 49: 604-20.

4. Johnson SJ, Hines JE, Burt AD. Macrophage and perisinusoidal cell kinetics in acute liver injury. J Pathol 1992; 166: 351-8

5. Sasaki S, Yoneyama H, Suzuki K, et al. Blockade of CXCL10 protects mice from acute colitis and enhances crypt cell survival. Eur J Immunol 2002; 32: 3197-205.

6. Morimoto J, Yoneyama H, Shimada A, et al. CXC chemokine ligand 10 neutralization suppresses the occurrence of diabetes in nonobese diabetic mice through enhanced beta cell proliferation without affecting insulitis. J Immunol 2004; 173: 7017-24.

7. Kalinichenko VV, Bhattacharyya D, Zhou Y, et al. Foxf1 +/mice exhibit defective stellate cell activation and abnormal liver regeneration following $\mathrm{CCl}_{4}$ injury. Hepatology 2003; 37: 107-17.

8. Pierce RA, Glaug MR, Greco RS, et al. Increased procollagen mRNA levels in carbon tetrachloride-induced liver fibrosis in rats. J Biol Chem 1987; 262: 1652-8.

9. Pérez Tamayo R. Is cirrhosis of the liver experimentally produced by $\mathrm{CCl}_{4}$ and adequate model of human cirrhosis? Hepatology 1983; 3: 112-20.

10. McCay PB, Lai EK, Poyer JL, et al. Oxygen- and carboncentered free radical formation during carbon tetrachloride metabolism. Observation of lipid radicals in vivo and in vitro. J Biol Chem 1984; 259: 2135-43.

11. Zheng YQ, Wei W, Zhu L, Liu JX. Effects and mechanisms of Paeoniflorin, a bioactive glucoside from paeony root, on adjuvant arthritis in rats. Inflamm Res 2007; 56: 182-8.

12. Zhang LL, Wei W, Wang NP, et al. Paeoniflorin suppresses inflammatory mediator production and regulates $G$ protein-coupled signaling in fibroblast-like synoviocytes of collagen induced arthritic rats. Inflamm Res 2008; 57 : 388-95.

13. Liu DF, Wei W, Song LH. Protective effect of paeoniflorin on immunological liver injury induced by bacillus Calmette-Guerin plus lipopolysaccharide: modulation of tumour necrosis factoralpha and interleukin-6 MRNA. Clin Exp Pharmacol Physiol 2006; 33: 332-9.

14. Wang H, Wei W, Wang NP, et al. Effects of total glucosides of peony on immunological hepatic fibrosis in rats. World J Gastroenterol 2005; 11: 2124-9.

15. Wu YG, Ren KJ, Liang C, et al. Renoprotective effect of total glucosides of paeony (TGP) and its mechanism in experimental diabetes. J Pharmacol Sci 2009; 109: 78-87.

16. Bujanda L, Hijona E, Larzabal M, et al. Resveratrol inhibits nonalcoholic fatty liver disease in rats. BMC Gastroenterol 2008; 8: 40.

17. Ohkawa H, Ohishi N, Yagi K. Assay for lipid peroxides in animal tissues by thiobarbituric acid reaction. Anal Biochem 1979; 95: 351-8.

18. Ismail NA, Okasha SH, Dhawan A, et al. Glutathione peroxidase, superoxide dismutase and catalase activities in hepatic tissue from children with glycogen storage disease. Arch Med Sci 2009; 5: 86-90.

19. Mihailovic M, Milosevic V, Grigorov I, et al. The radioprotective effect of alpha2-macroglobulin: A morphological study of rat liver. Med Sci Monit 2009; 15: BR188-93.
20. Prasad S, Singh K. Differential expression of Fmr-1 mRNA and FMRP in female mice brain during aging. Mol Biol Rep 2008; 35: 677-84.

21. Jabs DA, Gérard HC, Wei YW, et al. Inflammatory mediators in autoimmune lacrimal gland disease in MRL/Mpj mice. Invest Ophthalmol Vis Sci 2004; 45: 2293-8.

22. Lee HK, Kwak HY, Hur J, et al. Beta-catenin regulates multiple steps of RNA metabolism as revealed by the RNA aptamer in colon cancer cells. Cancer Res 2007; 67: 931521.

23. Siner JM, Jiang G, Cohen ZI, et al. VEGF-induced heme oxygenase- 1 confers cytoprotection from lethal hyperoxia in vivo. FASEB J 2007; 21: 1422-32.

24. Qin Y, Tian YP. A microarray gene analysis of peripheral whole blood in normal adult rats after long-term GH gene therapy. Cell Mol Biol Lett 2010; 15: 177-95.

25. Livak KJ, Schmittgen TD. Analysis of relative gene expression data using real-time quantitative PCR and the 2- $\Delta \Delta C T$ method. Methods 2001; 25: 402-8.

26. Qin Y, Tian YP. Preventive effects of chronic exogenous growth hormone levels on diet-induced hepatic steatosis in rats. Lipids Health Dis 2010; 9: 78.

27. Koch RR, Glende EA Jr, Recknagel RO. Hepatotoxicity of bromotrichloromethane-bond dissociation energy and lipoperoxidation. Biochem Pharmacol 1974; 23: 2907-15.

28. Edwards MJ, Keller BJ, Kauffman FC, Thurman RG. The involvement of Kupffer cells in carbon tetrachloride toxicity. Toxicol Appl Pharmacol 1993; 119: 275-9.

29. Wang H, Wei W, Wang NP, et al. Effects of total glucosides of peony on immunological hepatic fibrosis in rats. World J Gastroenterol 2005; 11: 2124-9.

30. Drotman RB, Lawhorn GT. Serum enzymes as indicators of chemically induced liver damage. Drug Chem Toxicol 1978; 1: 163-71.

31. El-Beshbishy HA. The effect of dimethyl dimethoxy biphenyl dicarboxylate (DDB) against tamoxifen-induced Liver injury in rats: DDB use is curative or protective. J Biochem Mol Biol 2005; 38: 300-6.

32. Lee KJ, Choi JH, Jeong HG. Hepatoprotective and antioxidant effects of the coffee diterpenes kahweol and cafestol on carbon tetrachloride-induced liver damage in mice. Food Chem Toxicol 2007; 45: 2118-25.

33. Blanco AM, Guerri C. Ethanol intake enhances inflammatory mediators in brain: role of glial cells and TLR4/IL-1RI receptors. Front Biosci 2007; 12: 2616-30.

34. Wang H, Wei W, Wang NP, et al. Effects of total glucosides of peony on immunological hepatic fibrosis in rats. World J Gastroenterol 2005; 11: 2124-9.

35. Otterbein LE, Choi AM. Heme oxygenase: colors of defense against cellular stress. Am J Physiol 2000; 279: L1029-L37. 